
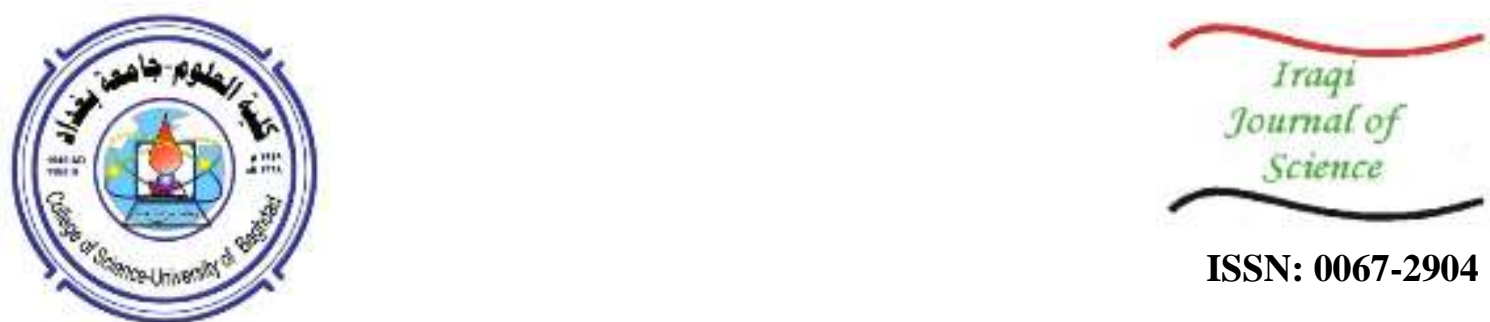

ISSN: 0067-2904

\title{
Prevalence of hyperandrogenism in Iraqi women with polycystic ovary syndrome
}

\author{
Yasmin L. Alsaadi", Ban Jasim Mohamad \\ Department of Biology, College of Science, University of Baghdad, Baghdad, Iraq
}

Received: 15/6/ 2019

Accepted: $27 / 7 / 2019$

\begin{abstract}
Polycystic ovary syndrome (PCOS) is a mainly common endocrine disorder. Hyperandrogenism is the major standard in the diagnosisof PCOS development.Eighty women diagnosed with PCOS and twenty healthy women(aged 20-40 years)were enrolled in this study which was conducted at the infertility clinic of Kamal AL-Samaraay Hospital/ Baghdad. The diagnosis of PCOS was made according to the Rotterdam criteria. Body mass index (BMI, $\mathrm{Kg} / \mathrm{m}^{2}$ ) was calculated by a specific formula. History of menstrual irregularity, hirsutism, acne, and alopecia was taken. Hormone levels in serum, namely luteinizing hormone (LH), follicle stimulating hormone (FSH), and testosterone were measured in all patients and control subjects.There was a statistically significant difference $(\mathrm{P}<0.05)$ in the BMI between the PCOS and control women.Also, the prevalence of overweight and obesity was much higher in PCOS women than in their matching control. The serum levels of LH, FSH, and testosterone were significantly different $(\mathrm{P}<0.05)$ in PCOS as compared to healthy women. Clinical hyperandrogenism (hirsutism and alopecia) were present in most of PCOS women, while acne wasa less useful clinical sign of hyperandrogenism.Inaddition, the prevalence of hirsutism and alopecia was increased in obese when compared with overweight and lean PCOS women.
\end{abstract}

Keywords: Polycystic ovary syndrome, Body mass index, Luteinizing hormone, Follicle stimulating hormone. Gonadotropin releasing hormone

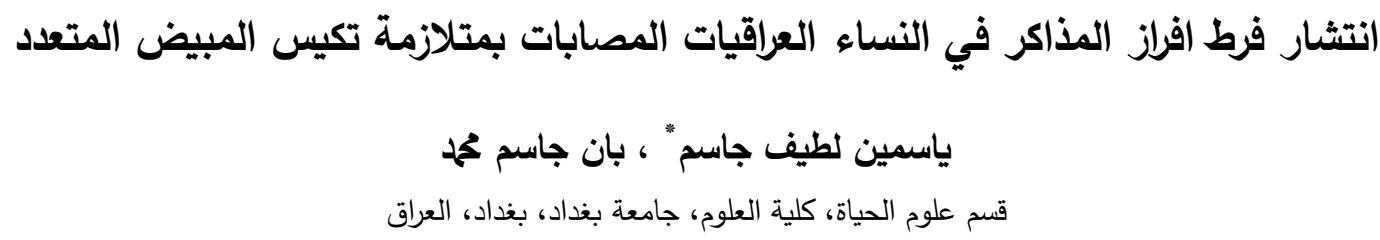

$$
\begin{aligned}
& \text { الخلاصة }
\end{aligned}
$$

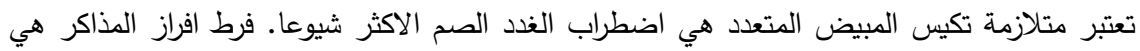

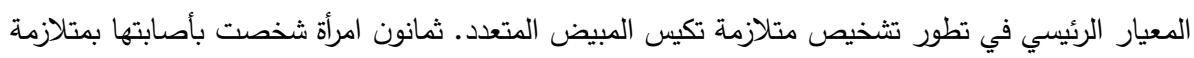

$$
\begin{aligned}
& \text { تكيس المبيض المتعدد و } 20 \text { امرأة غير مصابة، اعمارهم تتراوح بين (20-40) سنة تم تسجيلهم في هذها }
\end{aligned}
$$

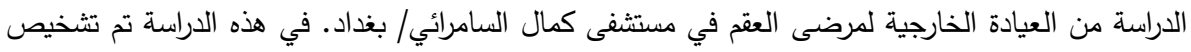

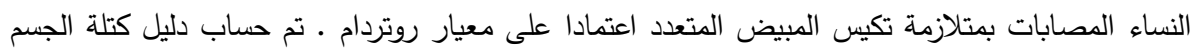

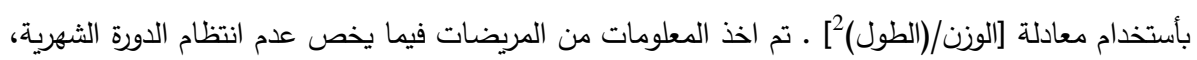

$$
\begin{aligned}
& \text { كثرة ظهور الثعر ، الحبوب في الوجه، وتساقط الثعر • تم قياس مستوى الهرمونات (الهزمون اللوتيني، }
\end{aligned}
$$

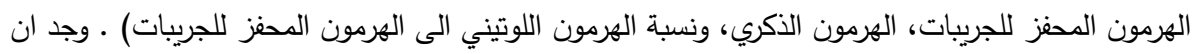




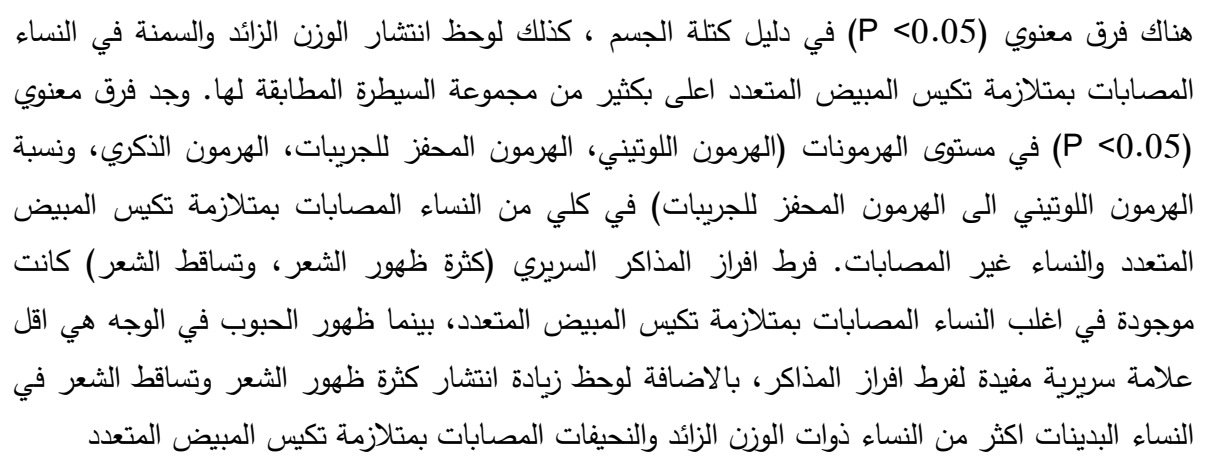

\section{1-Introduction}

Polycystic ovary syndrome (PCOS) is a widespread endocrine disorder affecting 5.6-21.3\% of women of reproductive age worldwide $[1,2]$. The diagnosis of PCOS was performed according to the Rotterdam criteria. This diagnosis was founded on two of the followingthree criteria: oligo- and/or anovulation, clinical hirsutism and/or high testosterone, and polycystic ovarian morphology as estimated through antransvaginal ultrasound [3]. Oligo-anovulation was defined by the connection between oligo-amenorrhea and a progesterone level less than or equal to $2 \mathrm{ng} / \mathrm{mL}$ in the luteal phase of the last cycle [4], while biochemical hyperandrogenism was defined by a testosterone level more than or equal to $0.454 \mathrm{ng} / \mathrm{mL}$ [5].

Androgen excess is a main pathophysiological characteristic of PCOS, with 60-80\% incidence [6]. Hirsutism is a familiar clinical appearance of hyperandrogenismreportedin up to $70 \%$ of women with PCOS [7].In typical women, androgens are secreted in approximately equal quantities by both adrenals and ovaries. On the other hand, androgen secretion from more than one source is familiar in $35 \%$ of women with PCOS.The ovary is the major androgen source in PCOS, while adrenal hyperandrogenism in PCOS is possibly the result of several factors including hyperinsulinemia, changed cortisol metabolism, and augmented ovarian steroid production [8]. In adult women with PCOS [9] and in hyperandrogenemic adolescents [10], androgen excess has been related with persistentlyaugmentedpulse rate of gonadotropin releasing hormone $(\mathrm{GnRH})$, which has been connected to the androgen-induced resistance of the GnRH pulse associated withnegative progesterone feedback. This irregularity could result in excessively elevated LH secretion, which may be responsible for ovarian androgen production and ovulatory dysfunction, causative to the adult PCOS phenotype $[11,12]$.

Hyperandrogenism is the most important criterion in the diagnosisof PCOS development. According to the present criteria, it can be unclearly defined by either hirsutism and/or excess of blood testosterone level. However, the majority but not all PCOS women are hirsute, and no more than 50\% have increased testosterone levels measured by the usually used immunoassay methods [13].

Objective: This study was designed to inspect the risk of PCOS in the modification of the hormonal profile, andto compare the clinical signs such hirsutism, acne, alopecia, and menstrual cycle dysfunction among lean, overweight and obese PCOS women.

\section{2-Materials and methods}

Eighty women already diagnosed with PCOS (by clinical and biochemical indication) and 20 agedmatched control women who had no clinical or hormonal abnormalities were recruited into the study. Subject's age ranged between 20 and 40 years.

Patients were examined and diagnosed as having PCOS by gynecologists at the outpatient clinic of Kamal AL-Samaraay Hospital/ Baghdad.

Anthropometry included the measurement of height, weight, and body mass index (BMI), according to the WHO guidelines shown in table 1. BMI was calculated by the routine formula: BMI $\left(\mathrm{kg} / \mathrm{m}^{2}\right)=$ weight $(\mathrm{Kg}) /[\text { height }(\mathrm{m})]^{2}[14]$. Weight in Kgs and height in meters were measured with an electronic scale.

Patients with PCOS had clinical illnesses of either: (1) Irregular menstrual cycles in the form of (oligomenorrhea, amenorrhea) (menstrual cycles $<21$ or $>38$ days), (2)Hirsutism, acne, or alopecia; hirsutism score by Ferimann Galloway scoring, or (3) Obesity.

Diagnosis of PCOS in the patients was confirmed by: 
- Ultrasound of the ovaries (presence of 8 or more sucapsular cysts $\leq 10 \mathrm{~mm}$ in diameter with augmented ovarian stroma).

- The laboratory results which included endocrine secretion evaluation by measurement of hormonelevels in serum, namely, luteinizing hormone (LH), follicle stimulating hormone (FSH), and Testosterone (T).Serum concentrations of three hormones were measured by using mini-VIDAS (VIDAS 12 model, 1992), through an enzyme linked fluorescent assay (ELFA) technique.

The exclusion criteria included the use of hormonal contraception, fertility medications in the three months prior to enrollment, hyperprolactinemia, thyroid dysfunction, cushing's syndrome, and congenital hyperplasia.

Statistical analysis of data was carried out using (SPSS Version 20). Significance of variances was assessed using t-test and a $\mathrm{P}$ value $\leq 0.05$ was considered to be significant.

Table 1- The international classification of adult underweight, overweight and obesity according to BMI (WHO, 2004).

\begin{tabular}{|c|c|c|}
\hline \multirow[t]{2}{*}{ Classification } & \multicolumn{2}{|c|}{ BMI (Kg $\left./ \mathrm{m}^{2}\right)$} \\
\hline & $\begin{array}{l}\text { Principal cut-ofif } \\
\text { points }\end{array}$ & $\begin{array}{l}\text { Additional cut-ofif } \\
\text { points }\end{array}$ \\
\hline Underweight & $<18.50$ & $<18.50$ \\
\hline Severe thinness & $<16.00$ & $<16.00$ \\
\hline Moderate thinness & $16.00-16.99$ & $16.00-16.99$ \\
\hline Mild thinness & $17.00-18.49$ & $17.00-18.49$ \\
\hline \multirow{2}{*}{ Normal range } & \multirow{2}{*}{$18.50-24.99$} & $18.50-22.99$ \\
\hline & & $23.00-24.99$ \\
\hline Overweight & $\geq 25.00$ & $\geq 25.00$ \\
\hline \multirow{2}{*}{ Pre-obese } & \multirow{2}{*}{$25.00-29.99$} & $25.00-27.49$ \\
\hline & & $27.50-29.99$ \\
\hline Obese & $\geq 30.00$ & $\geq 30.00$ \\
\hline \multirow{2}{*}{ Obese class I } & \multirow{2}{*}{$30.00-34.99$} & $30.00-32.49$ \\
\hline & & $32.50-34.99$ \\
\hline \multirow{2}{*}{ Obese class II } & \multirow{2}{*}{$35.00-39.99$} & $35.00-37.49$ \\
\hline & & $37.50-39.99$ \\
\hline Obese class III & $\geq 40.00$ & $\geq 40.00$ \\
\hline
\end{tabular}

\section{3-Results}

\section{Body mass index (BMI)}

An increase in BMI was found in PCOS patients as compared with the control group. There was a significant $(\mathrm{P}<0.05)$ difference in the mean of BMI between the PCOS group $\left(32.3 \pm 0.5 \mathrm{~g} / \mathrm{m}^{2}\right)$ and the control group $\left(28.8 \pm 1.0 \mathrm{~kg} / \mathrm{m}^{2}\right)$ as shown in table 2 .

Table 2- Comparison of BMI value in PCOS patients and control women.

\begin{tabular}{|l|c|c|}
\hline Studied group & No. & $\begin{array}{c}\text { BMI }\left(\mathbf{K g} / \mathbf{m}^{2}\right) \\
(\mathbf{m e a n} \pm \mathbf{S E})\end{array}$ \\
\hline PCOS patients & 80 & $(32.3 \pm 0.5)^{*}$ \\
\hline Control women & 20 & $(28.8 \pm 1.0)$ \\
\hline
\end{tabular}

-The difference between the two groups was statistically significant $(*=\mathrm{P}<0.05)$.

In the present study, we classified the body weight in the studied groups according to BMI, as shown in table 3. The prevalence of overweight and obesity in women with PCOS is much higher than in their matching control.

Table 3- The classification of body weight according to BMI in the studied groups.

\begin{tabular}{|c|c|c|}
\hline Body weight classification & PCOS patients $(\mathrm{n}=80)$ & Control group $(\mathrm{n}=20)$ \\
\hline Lean & $3(3.75 \%)$ & $11(55.0 \%)$ \\
\hline Overweight & $28(35.0 \%)$ & $5(25.0 \%)$ \\
\hline Obese & $49(61.25 \%)$ & $4(20.0 \%)$ \\
\hline Degree of significance & \multicolumn{2}{|c|}{$28.676^{*}$} \\
\hline
\end{tabular}

$(*=\mathrm{P}<0.05)=$ Significant $)$ 


\section{Clinical hyperandrogenism (Hirsutism, Acne, andAlopecia)}

It was found that the percentage of hirsutism in PCOS patients was $63.75 \%$; in lean $(3.92 \%)$, in overweight $(29.41 \%)$ and in obese $(66.67 \%)$. The percentage of acne was $30 \%$; in lean $(4.17 \%)$, in overweight $(29.17 \%)$ and in obese $(66.67 \%)$, while the percentage of alopecia was $65 \%$; in lean $(3.85 \%)$, in overweight $(30.77 \%)$ and in obese $(65.38 \%)$ (table 4$)$.

Table 4- Clinical hyperandrogenism and their relation to BMI in PCOS patients

\begin{tabular}{|c|c|c|c|c|c|}
\hline \multirow{2}{*}{$\begin{array}{c}\text { Clinical } \\
\text { hyperandrogenism }\end{array}$} & \multicolumn{4}{|c|}{ PCOS subgroups } & \multirow{2}{*}{$\begin{array}{c}\text { Degree of } \\
\text { significance }\end{array}$} \\
\hline & $\begin{array}{l}\text { Total } \\
\text { No. }\end{array}$ & Lean & Overweight & Obese & \\
\hline Hirsutism & $\begin{array}{c}51 \\
63.75 \%\end{array}$ & $\begin{array}{c}2 \\
3.92 \%\end{array}$ & $\begin{array}{c}15 \\
29.41 \%\end{array}$ & $\begin{array}{c}34 \\
66.67 \%\end{array}$ & $12.435^{*}$ \\
\hline Acne & $\begin{array}{c}24 \\
30.0 \%\end{array}$ & $\begin{array}{c}1 \\
4.17 \%\end{array}$ & $\begin{array}{c}7 \\
29.17 \%\end{array}$ & $\begin{array}{c}16 \\
66.67 \%\end{array}$ & $9.055^{*}$ \\
\hline Alopecia & $\begin{array}{c}52 \\
65.0 \%\end{array}$ & $\begin{array}{c}2 \\
3.85 \%\end{array}$ & $\begin{array}{c}16 \\
30.77 \%\end{array}$ & $\begin{array}{c}34 \\
65.38 \%\end{array}$ & $7.064^{*}$ \\
\hline
\end{tabular}

\section{$(* \mathbf{P}<0.05)=$ Significant}

\section{Menstrual cycle dysfunction}

In the present study, the whole PCOS group was split into three subgroups according to the menstrual status; fourteen patients were with eumenorrhea (17.5\%), eight patients were withabnormal uterine bleeding $(10.0 \%)$, forty seven patients were with oligomenorrhea $(58.75 \%)$ and eleven patients were with amenorrhea $(13.75 \%)$, as shown in table 5. The differences were significant $(\mathrm{P}<0.05)$ among lean, overweight, and obese PCOS patients.

Table 5- Menstrual cycle dysfunction in PCOS subgroups.

\begin{tabular}{|c|c|c|c|c|c|}
\hline \multirow{2}{*}{ menstrual status } & \multicolumn{4}{|c|}{ PCOS subgroups } & \multirow{2}{*}{$\begin{array}{c}\text { Degree of } \\
\text { significance }\end{array}$} \\
\hline & Total No. & Lean & Overweight & Obese & \\
\hline Eumenorrhea & $\begin{array}{c}14 \\
17.5 \%\end{array}$ & $\begin{array}{c}6 \\
42.86 \%\end{array}$ & $\begin{array}{c}8 \\
57.14 \%\end{array}$ & $\begin{array}{c}0 \\
0 \%\end{array}$ & $33.140^{*}$ \\
\hline $\begin{array}{l}\text { Abnormal uterine } \\
\text { bleeding }\end{array}$ & $\begin{array}{c}8 \\
10.0 \%\end{array}$ & $\begin{array}{c}0 \\
0 \%\end{array}$ & $\begin{array}{c}4 \\
50.0 \%\end{array}$ & $\begin{array}{c}4 \\
50.0 \%\end{array}$ & $33.140^{*}$ \\
\hline Oligomenorrhea & $\begin{array}{c}47 \\
58.75 \%\end{array}$ & $\begin{array}{c}3 \\
6.38 \%\end{array}$ & $\begin{array}{c}15 \\
31.91 \%\end{array}$ & $\begin{array}{c}29 \\
61.70 \%\end{array}$ & $33.140^{*}$ \\
\hline Amenorrhea & $\begin{array}{c}11 \\
13.75 \%\end{array}$ & $\begin{array}{c}0 \\
0 \%\end{array}$ & $\begin{array}{c}1 \\
9.09 \%\end{array}$ & $\begin{array}{c}10 \\
90.91 \%\end{array}$ & $33.140^{*}$ \\
\hline
\end{tabular}

\section{*P $<0.05=$ Significant}

\section{Hormonal measurements}

\section{Serum LH}

The meanserum level of LH within the control group was $3.2 \pm 0.2 \mathrm{mlU} / \mathrm{ml}$ whilst, in the PCOS patients, it was $7.8 \pm 0.6 \mathrm{mlU} / \mathrm{ml}$, as shown in Table-6. The difference between the twogroups was statistically significant $(\mathrm{P}<0.05)$.

\section{Serum FSH level}

The mean serum level of FSH for the control group was $7.1 \pm 0.4 \mathrm{mlU} / \mathrm{ml}$, whereas, in the group of PCOS patients, it was $4.2 \pm 0.5 \mathrm{mlU} / \mathrm{ml}$, as shown in table 6.The difference between the two groups was statistically significant $(\mathrm{P}<0.05)$.

\section{Serum testosterone level}

The mean serum level of testosterone within the control group was $0.3 \pm 0.03 \mathrm{ng} / \mathrm{ml}$, while, in the group of PCOS patients, it was $1.05 \pm 0.1 \mathrm{ng} / \mathrm{ml}$, as shown in table 6.The difference between the two groups was statistically significant $(\mathrm{P}<0.05)$. 


\section{LH/FSH ratio}

The LH/FSH ratio for patients with PCOS was $1.8 \pm 0.6$ and for the control group was $0.5 \pm 0.3$, with a significant difference between the two groups, as shown in table 6 .

Table 6- Comparison of hormonal levels in PCOS patients and control women.

\begin{tabular}{|c|c|c|}
\hline \multirow{2}{*}{ Parameters } & \multicolumn{2}{|c|}{ Mean \pm SE } \\
\cline { 2 - 3 } & Control women & PCOS patients \\
\hline LH $(\mathbf{m m o l} / \mathbf{L})$ & $(3.2 \pm 0.2)$ & $(7.8 \pm 0.6)^{*}$ \\
\hline FSH $(\mathbf{m l U} / \mathbf{m l})$ & $(7.1 \pm 0.4)$ & $(4.2 \pm 0.5)^{*}$ \\
\hline LH/FSH ratio & $(0.5 \pm 0.3)$ & $(1.8 \pm 0.6)^{*}$ \\
\hline Testosterone $(\mathbf{n g} / \mathbf{m l})$ & $(0.3 \pm 0.03)$ & $(1.05 \pm 0.1)^{*}$ \\
\hline
\end{tabular}

-The difference between the two groups was statistically significant

$(*=\mathrm{P}<0.05)$.

\section{4-Discussion}

Results of this study showed that women with PCOS had higher BMI than age-matched controls.Also, the prevalence of overweight and obesity was much higher in PCOS women than in their matching controls. Obesity condense the metabolic disorder and clinical criteria in women with PCOS. This finding was in agreement with a study by [15]whichindicated that obesity is a familiar morbidity associated with PCOS and that the accompanying insulin resistance is a key pathogenesis of PCOS. The relationship of obesity with PCOS was already illustrated, which gives insight into the expansion of typical criteria for obesity in PCOS. Similar results by other reports $[16,17]$ were concluded in women with PCOS, where mean BMI in PCOS women was significantly higher than the control groups. Valkenburg et al[18] revealed that obesity (BMI $\geq 30 \mathrm{~kg} / \mathrm{m}^{2}$ ) occurred more recurrently in PCOS women compared with the control group, while another study [19]indicated that the threat of PCOS is minimally enhanced with obesity, though the degree of obesity of PCOS patients has augmented, similar to that observed in women without PCOS in the present study. This information indicates that obesity in PCOS women reflects environmental factors to a great degree. Apridonidzeet al [20] stated that the increased weight and obesity (mostly abdominal) were widespread in women with PCOS, while another investigation found no difference in BMI between any of the PCOS groups and their matching controls[21].

Clinically, hyperandrogenic women with PCOS demonstratedhirsutism, acne, and temporal balding. The current study revealed that the frequency and percentage of clinical hyperandrogenism were augmented with increased BMI and that there were significant differences $(\mathrm{P}<0.05)$ in hirsutism, acne, and alopecia among lean, overweight, and obese PCOS patients. The clinical hyperandrogenism is augmented by overweight and obesity.We found that obese women with PCOS had a higher prevalence of clinical hyperandrogenism and, hence,obesity was considered to be responsible for hyperandrogenemia and the resulting hormonal abnormality and reproductive disorder in women with PCOS. These results agree with other authors [22] who found that PCOS women with obesityare susceptible to have higher hirsutism and acne signs than their lean counterparts. In fact, sex hormone binding globulin levels are decreased in obese women with PCOS, particularly if they present with abdominal obesity. It was found that overweight girls had significant hyperandrogenemia compared to their counterparts with normal weight[23], findings indicating that obesity plays an exciting role in the early progress of androgen excess, which may render PCOS more rapid. Corbould [24]reported that a key feature of PCOS is the increased levels of androgens. A side from their effects on ovarian function and phenotypical features, like alopecia, they also affect where fat is stored in the body.Majumdar and Singh [25] found that hyperandrogenism was present with hirsutism and acne was significantly higher in the overweight PCOS women.

A study conducted in Iran reported that women who had hirsutism were significantly more obese and younger than those without hirsutism [26]. Another study from Germany assessed the class of life reported by 120 PCOS women and the outcome revealed obesity and hirsutism to be associated to lower class of life scores [27]. 
It was alsoreported that the prevalence of menstrual irregularity and the clinical features of hyperandrogenism (hirsutism, acne, alopecia) were elevated in obese than in lean women with PCOS, but there was no statistically significant difference between the two studied groups[28].However, another study demonstrated that $42 \%$ of the PCOS women had typical BMI (lean), but the clinical signs (hirsutism and acne) were analogous to PCOS women with increased BMI (overweight/obese)[29].Norman et al [30] reported that PCOS is a varied endocrine disorder. The main endocrine disturbance is an extreme androgen secretion or activity, with frequent clinical signs of hyperandrogenism such as hirsutism, acne, and alopecia can appear as a result of hypersecretion of androgen by the ovary. Azziz et al[13]showed that about $60 \%$ of PCOS women are hirsute, which is the most common clinical feature of hyperandrogenemia. Ikhenaet al [31] mentioned thatscalp hair thinning is a prevalent sign in PCOS women. Tissue, rather than systemic endocrine environment appear to be of significance for scalp hair growth and density. Birchet al [32] found that PCOS women were six times more possible to distinguish scalp hair thinning compared with $6 \%$ incidence described in their matching controls. In the present study, we showed that $65.0 \%$ of PCOS patients had clinical signs of alopecia, while a previous study [33] reported that alopecia is common in $22 \%$ of women aggregating diagnostic criteria for PCOS. Androgenic alopecia is linked with other aspect of clinical hyperandrogenism, but not with more risk of biochemical hyperandrogenemia or metabolic disorder than with PCOS alone.

Menstrual disturbance was the main frequently present complaint in PCOS women. The present study showed that $82.5 \%$ of PCOS patients had clinical signs of menstrual disturbance (abnormal uterine bleeding, oligomenorrhea and amenorrhea) compared to $94 \%$ in a previous study [28]. Results of this study showed that obese PCOS women had a higher occurrence of menstrual dysfunction (abnormal uterine bleeding, oligomenorrhea, and amenorrhea) than lean and overweight PCOS women. This explains the fact that increased BMI was also associated with an increased rate of menstrual dysfunction.High serum levels of LH and testosterone in PCOS women may be associated with menstrual cycle dysfunction.

However, it was demonstrated that $79.2 \%$ of PCOS women with BMI > 23 and $44 \%$ of those with $\mathrm{BMI} \leq 23$ were with menstrual disturbance[25]. Other studies[22, 34, 35] showed that, as compared to non-obese PCOS women, obese women with PCOS have more menstrual irregularity and uterine dysfunctional bleeding, in additionto an increased occurrence of infertility, which were also related with an abdominal distribution of fat. Harris et al[36] reported that extended and irregular menstrual cycles, a feature of PCOS, was related with elevated androgen and slight sex hormone binding globulin levels, and that this altered hormonal environment may raise the risk of certain histologic ovarian cancer. Azzizet al[37]found that 75-85 \% of women with PCOS had clinically obvious menstrual disturbance, while another studyfound that $75 \%$ of PCOS patients were with clinically obvious menstrual disturbance[38]. It was reported thatirregular menstrual cycle was analogous in the lean and overweight/obese PCOS groups[29].

The results of LH, FSH, and testosterone levels as well as LH/FSH ratio in the present study were in agreement with the results of previous investigations [39-42] who showed that theelevations in testosterone and LH levels, accompanied by reducedFSH level and higher LH:FSH ratio, were the main endocrine changes observed in women with PCOS. Lewandowski et al[43] found that PCOS women have an increased speed of hypothalamic GnRH pulses, leading to an increase in the LH/FSH ratio. Ibrahim and Abdelsalam [44] reported in their study that a significant increase was found in LH, testosterone and LH/FSH ratio, while FSH level was insignificantlyincreased in PCOS women. Cascella et al[45], along with another study [46],reported that the level of LH was significantly elevated in PCOS women than in the control group, while the level of FSH did not alter significantly. In another study[47], elevated levels of FSH and LH were reported in PCOS women.Elevated LH relation to FSH was also documented in PCOS women compared with control subjects [48]. Furthermore, there wasa insignificant variation $(\mathrm{P}>0.05)$ in $\mathrm{LH} / \mathrm{FSH}$ ratio between the two groups.

\section{Conclusion}

Polycystic ovary syndrome is a frequent endocrinopathy disturbing women of reproductive age. It is the widespread reason of infertility. Moreover, more than half of the PCOS patients were obese. Based on the available data, clinicalsymptomssuch as menstrual cycle dysfunction and hyperandrogenism present with hirsutism, acne, and temporal balding were excessive in obese women with PCOS. However, the role of weight reduction is useful in the management of PCOS. This study 
clearly shows that the majority of patients with PCOS have high levels of testosterone and LH that seem to correlate with clinical hyperandrogenism in PCOS patients.

\section{References}

1. Sirmans, S.M. and Pate, K.A. 2014. Epidemiology, diagnosis, and management of polycystic ovary syndrome. Clin. Epidemiol. 6: 1-13.

2. Lizneva, D., Suturina, L., Walker, W., Brakta, S., Gavrilova-Jordan, L. and Azziz, R. 2016 Criteria, prevalence, and phenotypes of polycystic ovary syndrome. Fertil. Steril. 106: 6-15.

3. Rotterdam ESHRE/ASRM-Sponsored PCOS Consensus Workshop Group 2004.Revised 2003 consensus on diagnostic criteria and long-term health risks related to polycystic ovary syndrome (PCOS). Hum. Reprod. 19: 41-47.

4. Fanelli, F., Gambineri, A., Belluomo, I., Repaci, A., Di Lallo, V.D., Di Dalmazi, G., Mezzullo, M., Prontera, O., Cuomo, G. and Zanotti, L. 2013 Androgen profiling by liquid chromatographytandem mass spectrometry (LC-MS/MS) in healthy normal-weight ovulatory and anovulatory late adolescent and young women. J. Clin. Endocrinol. Metab. 98: 3058-3067.

5. Fanelli, F., Belluomo, I., Di Lallo, V.D., Cuomo, G., De Iasio, R., Baccini, M., Casadio, E., Casetta, B.; Vicennati, V.; Gambineri, A.; Grossi, G.; Pasquali, R. \&Pagotto, U. 2011 Serum steroid profiling by isotopic dilution-liquid chromatography-mass spectrometry: comparison with current immunoassays and reference intervals in healthy adults. Steroids.76: 244-253.

6. Azziz, R., Carmina, E., Dewailly, D., Diamanti-Kandarakis, E., Escobar-Morreale, H.F., Futterweit, W., Janssen, O.E., Legro, R.S., Norman, R.J., Taylor, A.E. and Witchel, S.F. 2006 Criteria for defining polycystic ovary syndrome as a predominantly hyperandrogenic syndrome: an androgen excess society guideline. J. Clin. Endocrinol. Metab. 91: 4237-4245.

7. Fauser, B. C., Tarlatzis, B.C., Rebar, R. W., Legro, R.S., Balen, A.H., Lobo, R., Carmina, E., Chang, J., Yildiz, B.O., Laven, J.S., Boivin, J., Petraglia, F., Wijeyeratne, C.N., Norman, R.J., Dunaif, A., Franks, S., Wild, R.A., Dumesic, D. and Barnhart, K. 2012 Consensus on women's health aspects of polycystic ovary syndrome (PCOS): the Amsterdam ESHRE/ASRM-Sponsored 3rd PCOS Consensus Workshop Group. Fertil. Steril. 97(1): 28-38. e25.

8. Carmina, E. 2006 Ovarian and adrenal hyperandrogenism. Ann. N. Y. Acad. Sci. 1092: 130-7.

9. Marshall, J.C. and Eagleson, C.A. 1999 Neuroendocrine aspects of polycystic ovary syndrome. Endocrinol. Metab.Clin. North Am. 28: 295-324.

10. Veldhuis, J.D., Pincus, S.M., Garcia-Rudaz, M.C., Ropelato, M.G., Escobar, M.E. and Barontini, M. 2001 Disruption of the joint synchrony of luteinizing hormone, testosterone, and androstenedione secretion in adolescents with polycystic ovarian syndrome. J. Clin. Endocrinol. Metab. 86: 72-79.

11. Chhabra, S., McCartney, C.R., Yoo, R.Y., Eagleson, C.A., Chang, R.J. and Marshall, J.C. 2005 Progesterone inhibition of the hypothalamic gonadotropin-releasing hormone pulse generator: evidence for varied effects in hyperandrogenemic adolescent girls. J. Clin. Endocrinol. Metab. 90: 2810-2815.

12. Eagleson, C.A., Gingrich, M.B., Pastor, C.L., Arora, T.K., Burt, C.M., Evans, W.S. and Marshall, J.C. 2000 Polycystic ovarian syndrome: evidence that flutamide restores sensitivity of the gonadotropin-releasing hormone pulse generator to inhibition by estradiol and progesterone. $J$. Clin. Endocrinol. Metab. 85: 4047- 4052.

13. Azziz, R., Carmina, E., Dewailly, D., Diamanti-Kandarakis, E., Escobar-Morreale, H.F., Futterweit, W., Janssen, O.E., Legro, R.S., Norman, R.J., Taylor, A.E. and Witchel, S.F. 2009. The Androgen Excess and PCOS Society criteria for the polycystic ovary syndrome: the complete task force report. Fertil. Steril. 91(2): 456-488.

14. WHO, 2004. expert consultation. Appropriate body mass index for asian population and its implications for policy and intervention strategies 2004. The Lancet. 157-163.

15. Lu, D. and Guo, X. 2016. Parameters of obesity in polycystic ovary syndrome. J. Rare Dis. Res. Treat. 2(1): 19-22.

16. Kyrkou, G., Trakakis, E., Attilakos, A., Panagopoulos, P., Chrelias, C., Papadimitriou, A., Vaggopoulos, V., Alexiou, E., Mastorakos, G., Lykeridou, A., Kassanos, D., Papaevangelou, V. and Papantoniou, N. 2016. Metabolic syndrome in Greek women with polycystic ovary syndrome 
prevalence characteristics and associations with body mass index A prospective controlled study. Arch Gynecol Obstet. 2934: 915-923.

17. Moran, L.J., Ranasinha, S., Zoungas, S., McNaughton, S.A., Brown, W.J. and Teede, H.J. 2013. The contribution of diet, physical activity and sedentary behaviour to body mass index in women with and without polycystic ovary syndrome. Hum. Reprod. 288: 2276-2283.

18. Valkenburg, O., Steegers-Theunissen, R.P.M., Smedts, H.P.M., Dallinga-Thie, G.M., Fauser, B.C.J., Westerveld, E.H. and Laven, J.S.E. 2008. A more atherogenic serum lipoprotein profile is present in women with PCOS: a case-control study. J. Clin. Endocrinol. Metab. 93: 470-476.

19. Yildiz, B.O., Knochenhauer, E.S. and Azziz, R. 2008. Impact of obesity on the risk for polycystic ovary syndrome. J. Clin. Endocrinol.Metab. 93: 162-168.

20. Apridonidze, T., Essah, P.A., Iuorno, M.J. and Nestler, J.E. 2005. prevalence and characteristics of the metabolic syndrome in women with polycystic ovary syndrome. J. Clin. Endocrinol. Metab. 90: $1929-1935$.

21. Deng, Y., Zhang, Y., Li, S., Zhou, W., Ye, L., Wang, L., Tao, T., Gu, J., Yang, Z., Zhao, D., Gu, W., Hong, J., Ning, G., Liu, W. and Wang, W. 2017. Steroid hormone profiling in obese and nonobese women with polycystic ovary syndrome. Sci. Rep. 7: 14156.

22. Gambineri, A.; Pelusi, C.; Vicennati, V.; Pagotto, U. \& Pasquali, R. 2002 Obesity and the polycystic ovary syndrome. Int. J. Obes. Relat. Metab. Disord. 26: 883-896.

23. McCartney, C. R.; Prendergast, K. A.; Chhabra, S.; Eagleson, C.A.; Yoo, R.; Chang, R.J.; Foster, C.M. \& Marshall, J.C. 2006 The association of obesity and hyperandrogenemia during the pubertal transition in girls: obesity as a potential factor in the genesis of postpubertalhyperandrogenism. J. Clin. Endocrinol. Metabol. 91: 1714-1722.

24. Corbould, A. 2007 Chronic testosterone treatment induces selective insulin resistance in subcutaneous adipocytes of women. J. Endocrinol. 192: 585-594.

25. Majumdar, A. \& Singh, T.A. 2009 Comparison of clinical features and health manifestations in lean vs. obese Indian women with polycystic ovarian syndrome. J. Hum. Reprod. Sci. 2: 12-17.

26. Khomami, M.B.; Tehrani, F.R.; Hashemi, S.; Farahmand, M. \&Azizi, F. 2015Of PCOS symptoms, hirsutism has the most significant impact on the quality of life of Iranian women. PLoS One.10(4): e0123608.

27. Açmaz,G.; Albayrak, E.; Acmaz, B.; Başer, M.; Soyak, M.; Zararsız, G. \& IpekMüderris,I. 2013 Level of anxiety, depression, self-esteem, social anxiety, and quality of life among the women with polycystic ovary syndrome.

28. Akshaya, S.\&Ratnaboli Bhattacharya 2016 Comparative study of clinical profile of lean and obese polycystic ovary syndrome women. Int. J. Reprod. Contracept Obstet. Gynecol. 5: 2530-2533.

29. Saxena, P.; Prakash, A.; Nigam, A. \& Mishra, A. 2012 Polycystic ovary syndrome: is obesity a sine qua non? a clinical, hormonal, and metabolic assessment in relation to body mass index. Indian J. Endocrinol.Metab.

30. Norman, R.J.; Dewailly, D.; Legro, R.S. \& Hickey, T.E. 2007 Polycystic ovary syndrome. Lancet. 370: $685-697$.

31. Ikhena, D.E.; Williams, J.; Naqvi, N. \& Pal, L. 2016 Predictors of scalp hair thinning in women with polycystic ovary syndrome. US Endocrinology. 12: 26-30.

32. Birch, M.P.; Messenger, I.F. \& Messenger, A.G. 2001 Hair density, hair diameter and the prevalence of female pattern hair loss. Br. J. Dermatol. 144: 297-304.

33. Quinn, M.; Shinkai, K.; Pasch, L.; Kuzmich, L.; Cedars, M. \& Huddleston, H. 2014 Prevalence of androgenic alopecia in patients with polycystic ovary syndrome and characterization of associated clinical and biochemical features. Fertil. Steril. 101:1129-1134.

34. Pasquali, R.; Gambineri, A.; \& Pagotto, U. 2006The impact of obesity on reproduction in women with polycystic ovary syndrome. B.J.O.G. 113: 1148-1159.

35. Hirschberg, A.L. 2009 Polycystic ovary syndrome, obesity and reproductive implications. Women's Health (Lond) 5: 529-540.

36. Harris, H.R.; Titus, L.J.; Cramer, D.W. \& Terry, K.L. 2017 Long and irregular menstrual cycles, polycystic ovary syndrome, and ovarian cancer risk in a population-based case-control study. Int. J. Cancer. 140: 285-291. 
37. Azziz, A.; Sanchez, L.A.; Knochenhauer, E.S.; Moran, C.; Lazenby, J.; Stephens, K.C.; Taylor, K. \& Boots, L.R. 2004 Androgen excess in women: experience with over 1000 consecutive patients. J. Clin. Endocrinol. Metab. 89: 453-462.

38. Hahn, S.; Tan, S.; Elsenbruch, S.; Quadbeck, B.; Herrmann, B.L.; Mann, K. \& Janssen, O.E. 2005 Clinical and biochemical characterization of women with polycystic ovary syndrome in North Rhine-Westphalia. Res. 37: 438-444.

39. Suresh, S.\& Vijayakumar, T. 2015 Correlations of insulin resistance and serum testosterone levels with LH:FSH ratio and oxidative stress in women with functional ovarian hyperandrogenism. Indian J. Clin. Biochem. 30: 345-350.

40. Huang, A.; Brennan, K. \& Azziz, R. 2010 Prevalence of hyperandrogenemia in the polycystic ovary syndrome diagnosed by the National Institutes of Health 1990 criteria. Fertil. Steril. 93: 1938-1941.

41. Stener-Victorin, E.; Holm, G.; Labrie, F.; Nilsson, L.; Per OlofJanson, P.O. \&Ohlsson, C. 2010 Are There Any Sensitive and Specific Sex Steroid Markers for Polycystic Ovary Syndrome? J.C.E.M. 95: 810-819.

42. Azziz, R. 2005 Diagnostic criteria for polycystic ovary syndrome: a reappraisal. Fertil. Steril. 83: $1343-1346$.

43. Lewandowski, K.C.; Cajdler-Luba, A.; Salata, I.; Bienkiewicz, M. \& Lewinski, A. 2011 The utility of the gonadotrophin releasing hormone $(\mathrm{GnRH})$ test in the diagnosis of polycystic ovary syndrome (PCOS). Endokrynol. Pol. 62: 120-128.

44. Ibrahim, W. \& Abdelsalam, K.E.A. 2015 Levels of FSH, LH, SHBG, total testosterone, and LH/FSH ratio in Sudanese patients with polycystic ovary syndrome in relation to body mass index. International Journal of current research. 7: 11919-11922.

45. Cascella, T.; Palomba, S.; De Sio, I.; Manguso, F.; Giallauria, F.; De Simone, B.; Tafuri, D.; Lombardi, G.; Colao, A. \& Orio, F. 2008 Visceral fat is associated with cardiovascular risk in women with polycystic ovary syndrome. Hum. Reprod. 23: 153-159.

46. Yesilada, E.; Sahin, I.; Ozcan, H.; Yildirim, I.H.; Yologlu, S. \&Taskapan, C. 2006 Increased micronucleus frequencies in peripheral blood lymphocytes in women with polycystic ovary syndrome. Eur. J.Endocrinol. 154: 563-568.

47. Hendriks, M.L.; Ket, J.C.F.; Hompes, P.G.A.; Homburg, R. \&Lambalk, C.B. 2007Why does ovarian surgery in PCOS help? Insight into the endocrine implications of ovarian surgery for ovulation induction in polycystic ovary syndrome. Hum. Reprod. 13: 249-264.

48. Chun, S. 2014 Serum luteinizing hormone level and luteinizing hormone/ follicle-stimulating hormone ratio but not serum anti-müllerian hormone level is related to ovarian volume in Korean women with polycystic ovary syndrome. Clinical and Experimental Reproductive Medicine. 41: $86-91$. 